Caligrama, Belo Horizonte, v. 23, n. 3, p. 83-98, 2018

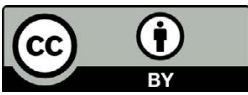

\title{
Mapear os significados contestados da identidade nacional angolana através da literatura pós-colonial
}

\section{Map the contested meanings of Angolan national identity through postcolonial literature}

\author{
Carolina Barros Tavares Peixoto \\ Universidad de Concepción, Concepción / Chile \\ carolina.peixoto@gmail.com
}

Resumo: O romance histórico Yaka, de Pepetela, narra o último século de administração portuguesa em Angola e as múltiplas resistências das populações nativas à ocupação colonial até a conquista da independência. Na construção da nação angolana, o pano de fundo do romance, uma narrativa sutil surge nas entrelinhas. Esse espaço liminar de representação articula as dificuldades de definição do que se tornaria representativo de uma ideia, ou um ideal, de "angolanidade" que foi construída concomitantemente à projeção da nação. A complexidade do enquadramento político e cultural que definiria a identidade nacional angolana decorre das experiências da história colonial, que, mais do que (re)inventar as fronteiras do que viria a ser a geografia política do país em busca da independência, teve um papel fundamental na definição do que constituiria o povo angolano - seja colocando juntos diferentes povos que originalmente habitaram esse vasto território, ou pelo assentamento de uma quantidade significativa de colonizadores brancos nos espaços conquistados. Depois de tantos anos de histórias e memórias compartilhadas entre colonizadores e colonizados, que características seriam consideradas como fontes legítimas de pertencimento nacional? Que fronteiras demarcaram a "angolanidade" funcionando como base para a construção da identidade nacional angolana? Quem teria direito à cidadania após o processo de independência? Estas questões orientaram o presente estudo de caso, que, ao ler Yaka como um romance histórico constitutivo das narrativas angolanas de pertencimento elaboradas já em uma conjuntura pós-colonial, reflete sobre os processos de exclusão/inclusão da população não negra na construção de uma ideia ou ideal de "angolanidade".

Palavras-chave: Pepetela; angolanidade; pertencimento; identidade nacional. 


\begin{abstract}
Pepetela's historical novel Yaka narrates the last century of Portuguese colonial presence in Angola and the multiple forms of resistance of native populations to colonial occupation until the conquest of independence. In the construction of the Angolan nation, the background of the novel, a subtle narrative appears between the lines. This liminal space of representation articulates the difficulties of defining what would become representative of an idea or an ideal of "Angolanity" that was constructed concomitantly with the projection of the Nation. The complexity of the political and cultural framework that would define Angolan national identity stems from the experiences of colonial history, which, more than (re)inventing the borders of what would become Angolan political geography, played a fundamental role in defining what would constitute the Angolan people - by putting together different peoples who originally inhabited this vast territory, or by the settlement of a significant population of white settlers in the conquered spaces. After so many years of stories and memories shared between colonizers and colonized, what characteristics would be considered as legitimate sources of national belonging? What frontiers demarcated the "Angolanity", functioning as a basis for the construction of Angolan national identity? Who would have the right to citizenship after the independence process? These questions guided the present case study which, reading Yaka as a historical novel constitutive of the Angolan narratives of belonging elaborated in a postcolonial conjuncture, reflects on the processes of exclusion/inclusion of the non-black population in the construction of an idea or ideal of "Angolanity".
\end{abstract}

Keywords: Pepetela; angolanity; belonging; national identity.

\title{
1 Introdução
}

Pepetela escreve Yaka aproveitando o fato de ter nascido no seio de uma família de colonos, numa cidade colonial, de ter lutado contra todas as formas de opressão empregadas pela administração portuguesa em Angola e de estar em sua cidade natal quando se conquista a independência, experiência que considera ser um "privilégio" (PEPETELA, [201-?]). O resultado deste exercício de escrita construído desde o lugar reconhecidamente privilegiado ocupado pelo autor, um angolano de ascendência portuguesa, é um romance histórico que traz à tona um profundo debate sobre a violência do encontro colonial e sobre suas repercussões e representações na sociedade angolana que ainda buscava consolidar sua autonomia, conquistada há menos de uma década, quando Yaka veio a público pela primeira vez. 
Embora os textos literários se distingam sempre por seus aspectos simbólicos, no caso do romance em questão o próprio autor destaca o fato de essa obra de ficção estar inserida num contexto histórico, político e cultural determinante para a sua produção. Yaka relata ficcionalmente os últimos cem anos da presença colonial portuguesa em Angola em paralelo com as múltiplas resistências das populações nativas à ocupação de seus territórios, o surgimento dos movimentos nacionalistas angolanos, a guerra de libertação nacional e a conquista da independência. Pepetela recorre à ficção para relacionar História e questão cultural assumindo uma perspectiva crítica que nos ajuda a relativizar a suposta verdade única dos discursos oficiais. No pano de fundo do romance, que é a narrativa da construção da nação angolana, uma questão se destaca, ainda que nas entrelinhas. É neste espaço liminar que Pepetela apresenta aos leitores as dificuldades inerentes ao processo de definição do que seria representativo de uma ideia de angolanidade ${ }^{1}$ que estava a ser arquitetada ao mesmo tempo em que se projetava a nação. Em 1974 a população branca residente em Angola era de meio milhão de pessoas, incluindo os militares e seus familiares (BENDER, 1978, p. 28). Um terço dessas pessoas havia nascido em Angola (FIGUEIREDO, 2012, p. 19). Tratava-se da segunda maior concentração de população branca em todo o continente africano, superada apenas pela da África do Sul. Conquistada a independência, em 11 de novembro de 1975, que lugares foram ocupados pelos ex-colonos e seus descendentes nascidos em território angolano? Depois de séculos de histórias e vidas compartilhadas entre colonos e colonizados, em que indicadores buscar a legitimidade do pertencimento a Angola? Diante da realidade multifacetada herdada da experiência colonial, a quem seria atribuído o estatuto de plena cidadania após a independência de Angola? Que características demarcariam a angolanidade funcionando como base para a construção de uma identidade nacional angolana? Ao longo deste trabalho procuraremos responder a estes questionamentos a partir da leitura de Yaka.

${ }^{1} \mathrm{O}$ conceito de angolanidade tem sido objeto de uma ampla variedade de debates literários, discussões históricas e disputas políticas sobre os processos de construção, representação e síntese da identidade nacional de Angola. Para uma visão panorâmica das reflexões e teorizações sobre a Angolanidade, entendida como aglutinadora das características e resultados da construção das identidades angolanas desde o início da luta armada pela libertação nacional (1961) até a consolidação da paz (2002) veja-se Batsîkama (2013). 
Os estudos pós-coloniais de recorte culturalista, com destaque para os trabalhos de Santos (2002; 2008), Bhabha (2007), Hall (2005) e Gilroy (2001), tiveram um papel particularmente relevante na construção da presente análise. Sobretudo no que diz respeito à interpretação dos conceitos de identidade e de cultura, que "não se apoia na existência prévia de unidades e identidades culturais, mas na articulação contingente de diferenças" (Costa, 2006, p. 18). Consideramos que Yaka pode ser compreendida como uma obra literária pós-colonial não só por ter sido produzida por um autor angolano após a consolidação da independência de seu país, mas, principalmente, por desvelar a complexidade inerente ao desenvolvimento do moderno nacionalismo em Angola, dado que a experiência colonial que teve lugar nessa parte de África propiciou o surgimento de distintos projetos de nação, inspirados por diferentes exercícios de identificação e variadas interpretações sobre a legitimidade da pertença à comunidade imaginada angolana. Neste romance Pepetela utiliza a ficção tanto para demonstrar como o discurso e as práticas coloniais construíram a polaridade entre o colonizador e o colonizado, quanto para, assim como faz o pós-colonialismo segundo Santos (2008, p. 236), "salienta[r] a ambivalência e a hibridez entre ambos já que não são independentes um do outro nem são pensáveis um sem o outro".

\section{Um retrato do encontro colonial numa obra literária pós-colonial}

Yaka conta a saga de Alexandre Semedo e sua família enquanto retrata os últimos anos da presença colonial portuguesa em Angola. História e ficção encontram-se magistralmente entrelaçadas nesta narrativa épica que leva o leitor a perceber o que foi o colonialismo, a partir de uma perspectiva angolana, e qual foi o ideal de nação que se tentou pôr em prática na altura da consolidação da independência de Angola.

A questão da idealização da nação enuncia-se desde a "Nota Prévia" que antecede ou abre o romance. Trata-se de uma nota explicativa sobre os yaka, também conhecidos como mbayaka, jaga ou imbangala. Povo guerreiro cuja história conhecida remonta ao século XVI. Esses habitantes do território angolano teriam sido "criadores de chefias, assimiladores de culturas, formadores de exércitos com jovens de outras populações que iam integrando na sua caminhada" (PEPETELA, 2010, p. 9), características que levam o autor a associá-los a um cazumbi ("espírito") antecipado da nacionalidade angolana. 
Contudo, o livro não trata dos yaka, aborda um período posterior da história angolana, um tempo em que estes guerreiros já haviam sido dizimados pelo colonialismo. No romance, Yaka é uma estátua, um vestígio da existência deste povo guerreiro, que acompanha Alexandre Semedo desde o seu nascimento até a sua morte. Ao longo do livro, Yaka e Alexandre vão dividindo com o autor - narrador onipresente - a função de narrar os últimos anos do colonialismo e os primeiros ensaios de construção de uma ideia de angolanidade.

O próprio romance fornece os principais instrumentos sóciohistóricos necessários a sua análise, uma vez que a estrutura do espaço social no qual se desenrola a saga dos Semedo é a mesma na qual o autor se encontra situado. Alexandre Semedo, assim como Pepetela, é um filho de colonos que vai se tornando angolano ao longo de sua trajetória, até ao ponto de ouvir Yaka, isto é, compreender a fala da terra. Mas até que o personagem principal atinja esse nível de compreensão da realidade angolana, que é também a sua, ou seja, que alimenta a sua identidade, transcorrem 85 anos.

Como em Retrato do colonizado precedido do retrato do colonizador (MEMMI, 1977), os principais protagonistas de Yaka são o colonizador e o colonizado. Interessante é notar como, a partir da ficcionalização da história, o romance demonstra claramente que era em função desses dois polos opostos que se estruturava a vida em Angola enquanto território colonizado, mas também que esses dois mundos inteiramente diversos, heterogêneos e irredutíveis um ao outro conviviam, ou "coabitavam", como bem observa Memmi.

O diálogo possível entre o romance aqui analisado e as reflexões registradas por Memmi no clássico supracitado parece confirmar-se quando analisamos seus personagens fictícios.

O velho barbeiro Acácio, amigo de Alexandre Semedo, pode ser interpretado como o que Memmi considerou ser o "colonizador de boa vontade". Anarquista, e por isso mesmo condenado ao degredo em Angola, ou seja, condenado a viver o privilégio de ser branco na colônia, Acácio manteve sua atitude ideológica e política mesmo no contexto colonial. Isto é, ele reconhecia a necessidade da libertação dos colonizados e da promoção da igualdade entre colonizadores e colonizados. Por defender publicamente seus ideais, Acácio acabou tendo um trágico fim, sendo espancado até a morte. A morte violenta era (e, infelizmente, continua sendo) um destino comum aos colonizados indulgentes. $\mathrm{O}$ narrador 
esclarece que um rico colonialista, grande proprietário de fazendas de café, tinha sido o mandante do bárbaro assassinato de Ácacio. Mas este nunca seria indiciado pelo crime. A impunidade era e, lamentavelmente, continua sendo uma realidade para os detentores do poder em todo o mundo.

$\mathrm{O}$ protagonista Alexandre Semedo parece ter sido construído à imagem e semelhança do "trânsfuga, nem colonizador nem colonizado" (MEMMI, 1977, p.50). Filho de um português degredado e de uma "branca de segunda" - designação pejorativa utilizada para identificar os brancos nascidos nas colônias portuguesas na África. Nascido em território cuvale (população nativa habitante do sudoeste angolano), sob uma árvore, talvez a mulemba (árvore sagrada para os cuvale). Ao escorregar das mãos da escrava que auxiliava o parto, o primeiro gesto do recém-nascido foi beijar/morder a terra. Terra que pode ser interpretada como primeira mãe, provedora do primeiro alimento e também do primeiro manto, já que o pó o envolveu concluindo simbolicamente este primeiro processo de adoção. Adoção que se confirmaria no final do romance e da vida de Alexandre. Ao morrer, Alexandre voltaria a beijar/ morder a terra, e seu espírito passaria a habitar a frondosa pitangueira existente no quintal de sua casa. Confirmando assim seu processo de ascensão à categoria de ancestral, conforme a cosmogonia dos povos banto. Ou seja, confirmando sua angolanidade.

Mas é apenas no nascimento e na morte que Alexandre vive, por breves instantes, a certeza de sua angolanidade. Enquanto trânsfuga, sua trajetória é marcada pela posição contraditória e insustentável que ocupa na sociedade colonial. Percebe que as relações coloniais não dependem da sua boa vontade ou do seu gesto individual; existiam antes de seu nascimento, quer as aceite ou as recuse não as modificará profundamente; são elas, ao contrário, que, como toda instituição, determinam a priori seu lugar e o do colonizado e, em definitivo, suas verdadeiras relações. Desconfia, embora não seja de modo algum culpado como indivíduo, que participa de uma responsabilidade coletiva, enquanto membro de um grupo opressor. Contudo, como afirma Memmi sobre o colonizador que tenta ser trânsfuga, ao recusar o mal, Alexandre

jamais poderá alcançar o bem, pois a única escolha que lhe é permitida não é entre o bem e o mal, é entre o mal e o mal-estar [...] tudo lhe fornece a prova de sua expatriação, de sua solidão e de sua ineficácia. Descobrirá lentamente que nada mais lhe resta senão calar-se (MEMMI, 1977, p. 50). 
Durante anos Alexandre viveria calado, comungando com Yaka a condição de estátua e um diálogo mudo porque ele não compreendia o que ela sempre lhe esteve a dizer. Só o bisneto Joel o faria romper o mutismo quando lhe ajudou a entender a mensagem de Yaka:

- A estátua representa um colono, avô. Repare bem. É o que o escultor pensava dos colonos. Ridículos. Veja o nariz. Burros e ambiciosos!

$[\ldots]$

- É uma sátira do colonialismo, avô.

- Por isso eles não gostam dela.

- Quem?

- Todos... O meu pai gostava... não se sentia colono. Pelo menos a princípio, no fim da vida não sei se ainda gostaria...

$-\mathrm{O}$ avô gosta.

- Sim. Mas incomodava-me. Depois deixou de me incomodar. Havia uma parte que me atraia e outra que me irritava. O ar irónico...

Ficou calado, perplexo. Como não tinha visto? Mesmo o miúdo tinha compreendido à primeira. Porque era miúdo?

- Também pressinto, avô, que ela fala de uma compreensão entre os homens. Mesmo se diferentes. (PEPETELA, 2010, p. 339)

Joel é “a exceção dos Semedo" (PEPETELA, 2010, p. 337). Será o primeiro membro da família Semedo assumidamente angolano. Ao optar por Angola ingressando nas fileiras do MPLA para lutar pela consolidação da independência, o bisneto realizará as aspirações mais profundas do completo trânsfuga que Alexandre nunca alcançou ser: aceitar totalmente aqueles pelos quais deseja ser adotado e ser adotado por eles (MEMMI, 1977, p. 46). Joel, não só fará parte das FAPLA - Forças Armadas Populares de Libertação de Angola -, que como os exércitos dos guerreiros jagas incorporava jovens de diferentes nações recrutados ao longo dos caminhos por onde passavam travando suas batalhas, como também será adotado pelos cuvale. Ao decidir fazer a guerra, consequentemente arriscando a própria vida pelo direito à angolanidade, Joel revela-se o herói moral da história ficcionalizada em Yaka.

No extremo oposto, Bartolomeu Espinha, genro de Alexandre Semedo, encarna o vilão da trama. Caricatura do colonialista tão bem retratado por Memmi, Bartolomeu é um metropolitano medíocre que vai para a colônia "porque nela as situações são garantidas, altos os 
ordenados, as carreiras mais rápidas e os negócios mais rendosos" (MEMMI, 1977, p. 22).

Uma vez instalado no papel social de colonizador, Bartolomeu recorrerá a todos os meios para fortalecer seu lugar e para não perdê-lo. Utilizando os meios mais vis e violentos da lógica de exploração colonial constrói um verdadeiro império particular. Como o colonialista retratado por Memmi, Bartolomeu "projeta sua existência na colônia em um tempo sem fim, pois nem por hipótese admite que um dia o colonizado possa sacudir o jugo a que se acha submetido" (MEMMI, 1977, p. 9). Neste sentido, mesmo às vésperas da independência, resistirá o maior tempo possível, porque quanto mais passa o tempo mais duram as vantagens, que bem merecem algumas inquietações e que sempre será cedo demais para perder. Só quando o perigo de ver-se espoliado de seus bens e destituído de sua posição social privilegiada torna-se iminente é que passa a pensar, seriamente, numa rota de fuga. Rota que desconsidera a metrópole como um destino possível. ${ }^{2}$ Afinal, na altura da independência de Angola, Portugal também vivia um processo revolucionário que abalava as estruturas da elite conservadora responsável pela manutenção, por mais de quatro décadas, de um governo ditatorial e colonialista. ${ }^{3}$ Seguido pela maior parte da família Semedo, Bartolomeu Espinha fugirá para a África do Sul, país onde vigorava o violento regime do Apartheid. Ou seja, onde qualquer indivíduo branco, independente de sua origem social ou condição econômica, era considerado superior aos negros pelo simples fato de ser branco.

\footnotetext{
${ }^{2}$ Segundo Almeida Santos (2006, p. 543), uma das consequências mais dramáticas e negativas do processo global de descolonização foi o mais expressivo êxodo, medido em percentagem sobre a população do país colonizador, dos impropriamente chamados retornados portugueses. Em relação a muitos deles, que já tinham nascido nos territórios colonizados, não se tratou de um retorno às origens, mas de uma deslocação forçada pelo clima de insegurança criado no processo de consolidação das independências. Como a situação política e econômica de Portugal em meados da década de 1970 era bastante instável, muitos ex-colonos optaram por outros destinos de migração. Ribeiro (2002, p. 404) destaca que, além de Portugal, Brasil, Canadá, EUA, África do Sul e Venezuela foram os principais países de destino dos ex-colonos que abandonaram as antigas possessões portuguesas na África fugindo da violência desencadeada durante o processo de descolonização.

${ }^{3}$ Revolução de 25 de Abril, também conhecida como Revolução dos Cravos ou Revolução de Abril, resultante do movimento político e social, ocorrido a 25 de abril de 1974, que depôs o regime ditatorial do Estado Novo, vigente desde 1933.
} 
Quando o bisneto Joel lhe revela que não partirá com o restante da família, Alexandre assume pela primeira vez que aquele também era o seu lugar no mundo e que ele também não deixaria a sua casa. Casa que não por acaso é um sapalalo - casa de madeira com dois andares, varandas externas e um amplo quintal interno, típica construção colonial utilizada como vivenda pelos colonos - em ruínas.

É no interior do sapalalo (e do coração) de Alexandre Semedo que habita a estátua Yaka, como a peça principal de seu acervo pessoal de arte africana. Esta africanização da casa colonial funciona como marca evidente do hibridismo e da polissemia cultural que, como nos faz ver Pepetela ao longo do romance, contribuem para a formação da identidade nacional angolana. Como bem observa Laura Cavalcante Padilha (2002, p. 71-72; p. 82), a narrativa encena as negociações de sentido, o encontro dos mundos europeu e africano do qual se originará, em turbulência, a nação angolana. O sapalalo é o espaço intersticial onde as fronteiras dos mundos do colonizador e dos colonizados deliberadamente se confundem. Representação da casa histórico-cultural angolana, implantada no terreno de uma realidade onde já não é possível sonhar com qualquer espécie de volta às origens, mas onde o presente se mescla com reminiscências do passado. É este presente repleto de passado que indica a importância de ressignificar a herança cultural herdada da experiência histórica da colonização para projetar o futuro de Angola independente. Neste sentido, Yaka oferece aos leitores outras chaves, talvez menos óbvias e por isso nem sempre experimentadas, para desvendar o segredo da complexa e multidimensional construção do que podemos chamar angolanidade.

Apesar de a história ser contada a partir do espaço colonial (o sapalalo) e enfocar a perspectiva de uma família de colonos, ela também dá voz aos excluídos, aqueles que normalmente são postos à margem da dita história oficial da colonização portuguesa na África. Os colonizados também são personagens do romance e, assim como os personagens que representam os colonizadores, podem ser lidos como protótipos dos retratos traçados por Memmi.

Tuca, o único amigo negro de Alexandre Semedo durante a infância, pode ser encarado como a personificação do "retrato real do colonizado". Aquele retrato mítico e degradante que de tão divulgado pelo colonizador acaba, em certa medida, por ser aceito e vivido pelo colonizado (MEMMI, 1977, p. 83). Tuca serviu ao exército colonial, tendo sido convocado para conter a revolta de Seles, onde os colonizados 
se insurgiram contra a espoliação das suas terras boas para o café. Ou seja, Tuca participou daquilo que o discurso colonial chamou de "campanhas de pacificação". Nada mais do que as guerras que dizimaram ou dispersaram as populações nativas permitindo o avanço da presença colonial pelo interior de Angola. Quanto ao fato de ter participado de uma "guerra (in)justa", Tuca guarda apenas a noção de ter cumprido o seu dever para com a pátria. Embora essa pátria fosse Portugal, a metrópole, que nunca reconheceria o direito à cidadania plena aos negros colonizados. Mesmo os que serviram ao exército português, seja nas ditas "campanhas de pacificação" do princípio do século XX, seja durante os 13 anos de guerra colonial (1961-1974), acabaram abandonados à própria sorte após cumprirem o serviço militar. Para a tropa negra não houve reformas. Porque aos colonizados cabiam todas as obrigações, mas nenhum direito.

Em contrapartida, o legendário personagem histórico Mutu-yaKevela, grande liderança da revolta dos bailundos de 1902, é rememorado em Yaka como um símbolo da resistência dos povos colonizados. Ainda que excluídas do núcleo principal enfocado pela narrativa, as várias revoltas das populações nativas, quase sempre recuperadas em forma de rememoração, vão desconstruindo a solidez do mundo centrado em si que é o mundo colonial. Tais revoltas significam sempre uma resposta dos negros mais conscientes - com frequência líderes tribais ou clânicos - frente às constantes tentativas empreendidas pelos colonizadores para usurpar as terras e bens dos colonizados.

Dessa forma, em paralelo com a história de prosperidade dos colonos as várias formas de violência e espoliação sofridas pelas populações autóctones durante o processo colonial também estão retratadas neste romance. Num jogo de causa e consequência, o trabalho escravo, o estupro das mulheres negras e os massacres em massa da população nativa para usurpar suas terras e seu gado são descritos como fatores responsáveis pela prosperidade dos colonos. Nesse sentido, o livro registra uma profunda crítica às práticas colonialistas levadas a cabo pelos portugueses em Angola.

Entretanto, a denúncia da violência em que se assentou a relação colonial é apenas um dos aspectos relevantes a serem considerados na análise desta obra. $\mathrm{O}$ outro é o registro de que a experiência colonial produziu uma espécie de "trasculturalismo" (HALL, 1996 apud CARREIRA, 2004, p. 2) cujos efeitos demonstraram ser irreversíveis. 
A morte violenta de Acácio, o ingresso de Joel nas fileiras do MPLA e o misterioso diálogo de uma vida inteira entre Alexandre Semedo e a estátua yaka demonstram que a cor da pele não é, necessariamente, uma barreira impeditiva da experiência de compartilhar culturas. Acácio era português, mas nos longos anos em que viveu no desterro em Angola sempre respeitou as populações locais e suas culturas. Pelas características violentas de sua morte, equiparou-se aos colonizados. Não por acaso seu desaparecimento físico foi lamentado por seus amigos, em sua maioria negros, num komba - funeral tradicional entre as populações nativas de Angola. A angolanidade de Joel nunca foi contestada. Afinal, como negar o direito de pertencimento à nação a um guerrilheiro que arrisca a vida pela liberdade da sua terra e do seu povo? Alexandre Semedo duvidou durante a maior parte de sua existência do seu direito à angolanidade. Direito que lhe foi outorgado pela própria terra quando o adotou como filho no momento de seu nascimento. Dúvida, a meu ver, oriunda de um profundo medo e vergonha de admitir e viver o amor que sentia por esta terra. Amor talvez personificável em Ndjaya, a jovem negra por quem ele se apaixona. Ndjaya despreza o desejo de Alexandre porque não quer viver a situação humilhante de ser amante de um branco que não está disposto a casar-se com ela. Mesmo assim, ele a respeita e não a viola. Apesar de considerar que poderia tê-lo feito, se quisesse. Nascido numa família de colonos, Alexandre tinha consciência dos privilégios que esta condição lhe imputava e desfrutava-os ainda que de forma passiva. Covarde, conviveu sempre com o eterno mal-estar de ser crítico de uma situação ao mesmo tempo que dela vivia. Nunca teve coragem de se sublevar contra a situação colonial. Ao morrer, a terra, mãe que a tudo perdoa, perdoou-lhe a covardia recebendo-o como o bom filho que à casa torna.

A história desss três personagens brancos angolanos ou que se angolanizam ao longo de suas trajetórias pessoais corrobora o fato de que, como destaca Stuart Hall (2006, p. 48-51), as identidades nacionais não são coisas com as quais nós nascemos, mas são formadas e transformadas no interior dos sistemas de representação cultural que compartilhamos. As pessoas não são apenas cidadãs legais de uma nação; elas participam da ideia da nação tal como representada em sua cultura nacional. Uma cultura nacional é um modo de construir sentidos que influencia e organiza tanto nossas ações quanto a concepção que temos de nós mesmos. As culturas nacionais, ao produzirem sentidos sobre 
"a nação", sentidos com os quais podemos nos identificar, constroem identidades nacionais.

Segundo Stuart Hall (2006, p. 62), “as nações modernas são, todas, híbridos culturais". Como podemos perceber a partir da leitura de Yaka, Angola não escapa a esta regra. O diferencial do caso angolano em relação ao das demais nações modernas seria o projeto de nação imaginado ao longo do processo de luta pela independência. Para Hall (2006, p. 59), a maioria das nações consiste de culturas separadas, que só foram unificadas pela supressão forçada da diferença cultural. $\mathrm{Na}$ perspectiva de Pepetela plasmada nas páginas do romance que aqui analisamos, a nação angolana constituir-se-ia da comunhão fraterna das diferentes culturas existentes no interior de Angola.

É Laura Cavalcante Padilha quem nos ajuda a compreender o último enigma contido em Yaka:

como recortar os conceitos colonizador/colonizado no processo de dominação imperialista português [?]. Dito de outro modo, como entender o que sempre foi uma ficção sobre o sentido do colonialismo português, pois a ideia mesma de uma hegemonia lusíada nunca passou de um mito recriado? (PADILHA, 2002, p. 77)

O que Pepetela põe em causa ao longo das páginas deste romance histórico são os engodos contidos no processo colonial como um todo e a exclusão histórica a que têm sido relegados os colonizados e mesmo os colonos. Isto é, os atores que representaram no cenário colonial propriamente dito a narrativa ao mesmo tempo mistificada e mistificadora do colonialismo. Ao ressignificar acontecimentos, relativizar procedimentos e dialetizar propostas, o romance revela o complexo processo pelo qual o território colonizado vai transformar-se num Estado-Nação independente ao mesmo tempo em que seus habitantes tornam-se cidadãos.

\section{Considerações finais}

A leitura de Yaka nos permite tirar partido de propriedades típicas do discurso literário - como a capacidade de desvelar velando ou de produzir um "efeito real" ficcionalizando -, para introduzir uma perspectiva mais complexa ao exercício de análise da história 
contemporânea de Angola. Ao nos ajudar a conhecer a história de Angola em maior profundidade, consequentemente, a leitura desta obra contribui também para uma melhor percepção da atual conjuntura angolana, uma vez que ilustra a complexidade desse passado recente e nos permite enxergar suas marcas no presente.

Yaka constitui um excelente exemplo de como a Literatura tem se destacado como um espaço privilegiado de (re)construção de uma memória pós-colonial que denuncia e critica os efeitos da "colonialidade do saber, do poder e do ser" (QUIJANO, 2009) na sociedade angolana, enquanto, de modo geral, a produção historiográfica sobre Angola continua muito marcada pela versão dos "vencedores". Ao analisar essa obra literária desde uma perspectiva pós-colonial situada que enfoca os processos históricos de colonização e descolonização de Angola e o modo como as práticas e os discursos característicos do colonialismo português influenciaram a construção das identidades nas sociedades que dele participaram, tanto durante o período colonial como depois da independência das colônias (SANTOS, 2002), percebemos que esse romance levanta reflexões que continuam sendo pertinentes na Angola contemporânea, como a questão do pertencimento a uma ideia ou ideal de angolanidade. Tema que tanto inspirou como desafiou os vários movimentos nacionalistas que se envolveram na luta pela independência de Angola e que, assim como outras heranças coloniais, transcendeu a conquista da soberania e da autonomia angolanas.

Como destaca Amina Mama (2007), em grande parte da África as identidades nacionais sempre foram mal alicerçadas e sujeitas a uma permanente contestação, nunca logrando sobrepor-se ao pulsar multiétnico, multilíngue e multirreligioso do continente. Com a angolanidade não seria diferente. Em Angola, a luta anticolonial foi marcada pela ambiguidade entre a ideia homogeneizadora da angolanidade ligada a um projeto nacional inspirado nos ideais da modernidade e a realidade heterogênea fortemente marcada por outras narrativas, tais como a questão etnolinguística, a questão racial e as diversidades regionais, culturais e religiosas que nunca deixaram de fazer parte da vida dos habitantes do país. Entretanto, como nenhuma dessas outras identidades comunitárias contou com estruturas institucionais que lhes permitissem consolidarem-se no mundo moderno, elas foram adquirindo e perdendo aceitação ao sabor da variável sorte política angolana. Num primeiro momento chegaram a ser acionadas pelos movimentos nacionalistas numa tentativa de agregar 
o maior número possível de militantes na luta anticolonial. Depois, foram relegadas como sinônimo de "atraso" diante de um projeto de nação que se queria moderno. A difusão de uma concepção homogeneizadora dos critérios definidores da angolanidade promoveu o silenciamento de uma diversidade de memórias geradas pelas sempre complexas interações sociais estabelecidas entre colonizadores e colonizados, contribuindo assim para escamotear uma variedade de tensões e antagonismos que permeavam (e ainda permeiam) a sociedade angolana.

As profundas imbricações entre o esforço de monopolização da história e as disputas sobre a ideologia, a cultura, a questão das identidades, incluindo a própria identidade nacional, que seguem tendo lugar na esfera hegemônica da qual permanece excluída grande parte da população angolana, assim como o fato de que, sobre essas questões, há presentemente lugar um debate que tem levantado várias polêmicas como a que se refere ao papel dos angolanos de ascendência portuguesa na luta pela libertação nacional e no processo de consolidação da independência, por exemplo, continuam a influenciar a (re)construção da história contemporânea de Angola (PEIXOTO, 2015). Daí a necessidade de investir na produção de uma história pós-colonial contra-hegemônica, que incorpore múltiplas interpretações e valorize as diversas relações oriundas de processos de diálogo, cooperação e, inclusive, confronto, e numa "sociologia das ausências" (SANTOS, 2008, p. 246), que, centrando-se nos fragmentos da experiência social não socializados pela leitura totalitária da realidade, permita "transformar objetos impossíveis em possíveis e com base neles transformar as ausências em presenças" (SANTOS, 2008, p. 246).

\section{Referências}

BATSÎKAMA, P. Angolanidade: construção das identidades angolanas, Por dentro da África, [S.1.], 10 set. 2013. Cultura. Disponível em: $<$ http:// www.pordentrodaafrica.com/cultura/angolanidade-construcao-dasidentidades-angolanas-por-patricio-batsikama>. Acesso em: 18 set. 2018.

BENDER, G. J. Angola under the Portuguese: The Myth and the Reality. Berkeley: University of California Press, 1978.

BHABHA, H. K. O local da cultura. Belo Horizonte: Editora UFMG, 2007. 
CARREIRA, S. de S. G. Narrar a nação: um projeto além da utopia. In: CONGRESSO LUSO-AFRO-BRASILEIRO DE CIÊNCIAS SOCIAIS. 8., 2004, Coimbra. Anais... [S.1.]: [s.n.], 2004, Disponível em: <https:// www.ces.uc.pt/lab2004/pdfs/ShirleyCarreira.pdf>. Acesso em: 19 maio 2011.

FIGUEIREDO, L. Luanda 1974/1975: o Movimento Estudantil. Óbidos: Sinapis, 2012.

GILROY, P. O Atlântico Negro: modernidade e dupla consciência. São Paulo: Editora 34; Rio de Janeiro: Universidade Cândido Mendes, Centro de Estudos Afro-Asiáticos, 2001.

HALL, S. As culturas nacionais como comunidades imaginadas. In: . A identidade cultural na pós-modernidade. Rio de Janeiro: DP\&A, 2006. p. 47-65.

HALL, S. Quem precisa da identidade?. In: SILVA, T. T. da (Org.). Identidade e diferença: a perspectiva dos estudos culturais. Petrópolis: Vozes, 2005. p. 103-133.

MAMA, A. Is It Ethical to Study Africa? Preliminary Thoughts on Scholarship and Freedom, African Studies Review, Cambridge, New York, v. 50, n. 1, p. 1-26, 2007.

MEMMI, A. Retrato do colonizado precedido pelo retrato do colonizador. 2. ed. Rio de Janeiro: Paz e Terra, 1977.

PADILHA, L. C. O Sapalalo ou uma casa entre dois mundos em Benguela. In: Novos pactos, outras ficções: ensaios sobre literaturas afroluso-brasileiras. Lisboa: Novo Imbondeiro, 2002. p. 71-82.

PEIXOTO, C. B. T. Ser, não ser, voltar a ser ou tornar-se? Uma reflexão sobre a (re)inserção social dos angolanos de ascendência portuguesa à luz dos estudos pós-coloniais. 2015. 320 f. Tese (Doutorado em Pós-colonialismos e Cidadania Global) - Faculdade de Economia, Universidade de Coimbra, Coimbra, 2015.

PEPETELA. "O Escritor é um ditador no momento da escrita”. União dos Escritores Angolanos, Luanda, [201-?]. Entrevistas. Entrevista concedida a Aguinaldo Cristóvão. Disponível em: <http://www.ueangola.com/ index.php/entrevistas/item/384-o-escritor-\%C3\%A9-um-ditador-nomomento-da-escrita.html>. Acesso em: 19 maio 2011. 
PEPETELA. Yaka. Alfragide: D. Quixote, 2010.

QUIJANO, A. Colonialidade do poder e classificação social. In: SANTOS, B. de S.; MENESES, M. P. (Org.) Epistemologias do Sul. Coimbra: Almedina, 2009. p. 73-117.

RIBEIRO, G. A vertigem da descolonização: da agonia do êxodo à cidadania plena. Mem Martins: Editorial Inquérito, 2002.

SANTOS, A. Quase memórias. Braga: Círculo de Leitores, 2006. v.1.

SANTOS, B. de S. A gramática do tempo: para uma nova cultura política. 2. ed. São Paulo: Cortez, 2008.

SANTOS, B. de S. Entre Próspero e Caliban. Colonialismo, póscolonialismo e inter-identidade. In: RAMALHO, M. I.; RIBEIRO A. S. (Org.). Entre ser e estar: raízes, percursos e discursos da identidade. Porto: Afrontamento, 2002. p. 23-85.

Recebido em: 16 de julho de 2018. Aprovado em: 23 de outubro de 2018. 